University of South Carolina

Scholar Commons

$11-2011$

\title{
Social and clinical predictors of prostate cancer treatment decisions among men in South Carolina
}

\author{
Sara E. Wagner \\ Bettina F. Drake \\ Keith Elder \\ James R. Hébert \\ University of South Carolina - Columbia, jhebert@sc.edu
}

Follow this and additional works at: https://scholarcommons.sc.edu/

sph_epidemiology_biostatistics_facpub

Part of the Public Health Commons

\author{
Publication Info \\ Postprint version. Published in Cancer Causes and Control, Volume 22, Issue 11, 2011, pages 1597-1606. \\ Wagner, S.E., Drake, B.F., Elder, K., \& Hébert, J.R. (2011). Social and clinical predictors of prostate cancer \\ treatment decisions among men in South Carolina. Cancer Causes and Control, 22(11), 1597-1606. DOI: \\ 10.1007/s10552-011-9836-2 \\ (C) 2011 Springer Science+Business Media B.V. \\ The final publication is available at www.springerlink.com.
}

This Article is brought to you by the Epidemiology and Biostatistics at Scholar Commons. It has been accepted for inclusion in Faculty Publications by an authorized administrator of Scholar Commons. For more information, please contact digres@mailbox.sc.edu. 


\title{
Social and clinical predictors of prostate cancer treatment decisions among men in South Carolina
}

\author{
Sara E. Wagner, Bettina F. Drake, Keith Elder, and James R. Hébert \\ Department of Epidemiology and Biostatistics, College of Public Health, Paul D. Coverdell Center \\ for Biomedical and Health Sciences, University of Georgia, 500 D.W. Brooks Drive, Athens, GA \\ 30602-7396, USA, swagner@uga.edu \\ Division of Public Health Sciences, Department of Surgery, Washington University School of \\ Medicine, St. Louis, MO, USA; Alvin J. Siteman Cancer Center, Washington University School of \\ Medicine, St. Louis, MO, USA \\ School of Public Health, Department of Health Management and Policy, Saint Louis University, \\ St. Louis, MO, USA \\ Arnold School of Public Health, Department of Epidemiology and Biostatistics, University of South \\ Carolina, Columbia, SC, USA; South Carolina Statewide Cancer Prevention and Control \\ Program, Columbia, SC, USA
}

\section{Abstract}

Objective-To assess social and clinical influences of prostate cancer treatment decisions among white and black men in the Midlands of South Carolina.

\begin{abstract}
Methods-We linked data collected on treatment decision making in men diagnosed with prostate cancer from 1996 through 2002 with clinical and sociodemographic factors collected routinely by the South Carolina Central Cancer Registry (SCCCR). Unconditional logistic regression was used to assess social and clinical influences on treatment decision.
\end{abstract}

\begin{abstract}
Results-A total of 435 men were evaluated. Men of both races who chose surgery (versus radiation) were more likely to be influenced by their physician and by family/ friends. Black men who chose surgery also were $\sim 5$ times more likely to make independent decisions (i.e., rather than be influenced by their doctor). White men who chose surgery were twice as likely to be influenced by the desire for cure and less likely to consider the side effects of impotence (odds ratio $(\mathrm{OR})=$ $0.40 ; 95 \%$ confidence interval (CI): $0.18,0.88$ ) and incontinence (OR $=0.27 ; 95 \% \mathrm{CI}: 0.12,0.63$ ); by contrast, there was a suggestion of an opposite effect in black men, whose decision regarding surgery tended to be more strongly influenced by these side effects.
\end{abstract}

Conclusion-Results suggest that both clinical and social predictors play an important role for men in choosing a prostate cancer treatment, but these influences may differ by race.

\section{Keywords}

Prostatic neoplasms; Minority health; Decision making

(C) Springer Science+Business Media B.V. 2011

Electronic supplementary material The online version of this article (doi:10.1007/s10552-011-9836-2) contains supplementary material, which is available to authorized users. 


\section{Introduction}

Patients diagnosed with prostate cancer are generally presented with three options for treatment: watchful waiting, radical prostatectomy, or radiotherapy (external beam or brachytherapy). Other options include cryosurgery, hormonal therapy, or some type of complementary or alternative medicine. However, no convincing evidence exists to recommend one prostate cancer treatment over another [1]. Often, patients are encouraged to take an active role in the decision-making process to choose a course of treatment. However, the process they use to determine their preference may not be systematic and typically is influenced by a number of clinical and social factors.

Although the most important issue influencing treatment choice varies widely among patients, some considerations are more frequently noted as important throughout the literature. Treatment efficacy and side effects are primary concerns for patients choosing between treatments. While longevity and cancer control are important to most patients [2-6], these patients are often willing to trade some longevity for better quality of life, specifically through an avoidance of impotence and incontinence [7, 8]. Maintaining a balance between treatment efficacy and the avoidance of side effects is dependent on a patient's perceptions of a particular treatment, each having its own advantages and disadvantages.

Surgery (prostatectomy) and radiation (radiotherapy), two of the most common treatment courses for prostate cancer, have distinct advantages and disadvantages and raise different concerns with patients. Patients who choose prostatectomy seem to believe strongly that it represents the best chance of a cure or is the best for longevity [9-12]. These patients frequently report complete removal of the tumor as a reason that prostatectomy is more attractive than other treatments $[5,11,13]$, but concerns most frequently reported for surgery are fears of impotence and incontinence and dislike of procedure invasiveness [11, 14]. Men who undergo surgery for prostate cancer treatment have higher rates of both incontinence and impotence compared to men who choose other options [15]. Patients who choose radiotherapy report their primary reason for treatment choice is their belief that radiotherapy is less painful, less invasive, and has fewer, less severe side effects [9-14].

A few studies have examined the role that social factors play in influencing treatment decisions. Social influences are likely an important component of the decision-making process for cancer patients and may include personal beliefs and opinions of family, friends, and physicians. Family and friends often urge men to pursue more active treatments [16], but the opinions of others who have had cancer treatment and physicians seem to be the most influential $[5,9,14,17-20]$. The extent to which social factors influence men to choose certain treatment types is not well understood.

A few studies have looked for racial differences in factors influencing treatment decision making. In general, racial differences exist in the type of treatment chosen, with black men more likely to choose non-surgical options compared to white men [19,21]. While it is unclear why these differences exist, some hypothesize that physicians may provide black men with different information, either because they think these men will not adhere to medical advice or that they will be less receptive to surgery [19,21]. These treatment choice disparities also may be a result of physician distrust among black men [22], economic or social vulnerability, or variation in how black and white men weigh the advantages and disadvantages of treatment choices [23]. More research is needed in this area, especially because black men have been found to have significantly higher rates of prostate cancer incidence and mortality than any other racial or ethnic group [24].

The purpose of this study was to assess the influence of social factors and clinical side effects on prostate cancer treatment choices among black and white men in the Midlands 
Region of South Carolina. South Carolina is well suited for this study because of the large proportion of black men and high rates of prostate cancer. In fact, the age-adjusted prostate cancer mortality rate among black men in South Carolina is among the highest nationwide [25]. Specifically, we examined the influence of these factors in predicting surgery versus radiation with data obtained through a short mail questionnaire. This study also assessed these relationships by race.

\section{Methods}

\section{Study cohort}

We mailed the questionnaires to men in South Carolina with a previous diagnosis of prostate cancer from an eight-county area in the Midlands of South Carolina (Calhoun, Fairfield, Kershaw, Lexington, Newberry, Orangeburg, Richland, and Sumter counties) identified through the South Carolina Central Cancer Registry (SCCCR). All men diagnosed between 1996 and 2002 were eligible to participate. Both physician and participant consent was required to participate in the survey. The SCCCR did not release any participant's information in which the patient requested not to be contacted or refused participation in previous research studies. Subsequently, we received a total of 2,079 prostate cancer cases from the SCCCR.

During the mailing, 103 (5\%) questionnaires were undeliverable due to incorrect addresses or death of the patient. Of those remaining, 1,416 (68\%) did not respond after two attempts to make contact and 9 cases refused to participate. In total, 551 surveys were returned, yielding a $28 \%$ response rate $(551 / 1,976)$.

\section{Study procedures}

Protocols outlined by the Cancer Control Advisory Committee-Surveillance Subcommittee, the SCCCR, the South Carolina Department of Health and Environmental Control, and the University of South Carolina Institutional Review Board were implemented to ensure and maintain confidentiality of prostate cancer patients. Each participant received a cover letter and survey with a return, self-addressed, stamped envelope. After 1 month, patients who did not return the survey received a follow-up letter and survey. After 2 months of nonresponse, the last attempt was made by mailing the final cover letter and survey.

We linked data from the survey with clinical and sociodemographic factors identified in the SCCCR. Variables obtained from the registry included age at diagnosis, date of birth, race/ ethnicity, county of residence, marital status, diagnosis year, number of previous cancer diagnoses, and disease grade and stage categorized according to American Joint Committee on Cancer [26] staging and histologic grading system for prostate cancer. The grading system is a marker of pathologic disease severity and ranges with increasing severity from 1 to 4 . The stage of a cancer describes to what extent the cancer has spread. The four levels of stage include local (organ confined), regional (extraprostatic extension), distant (invasion of surrounding organs), or unknown [26].

\section{Study assessments}

The survey was one-page and included twelve questions designed to determine the type of treatment(s) received and factors that may have affected the decision for choosing a particular treatment type (Online Resource 1). The survey was created in an optical-scan program, Teleform ${ }^{\circledR}$, to assist in survey design and data entry. Exposure variables obtained from the survey included the person who most influenced the treatment decision, clinical factors influencing the decision, prostate-specific antigen (PSA) level change, type of insurance, and access to healthcare. 
The outcome, type of treatment selected, was obtained from the survey. Initial treatment was categorized as surgery, radiation, chemotherapy, hormone therapy, no treatment (watchful waiting), and unknown. Change in PSA was determined by self-report of at least one increase in PSA since receiving cancer treatment. Living with a partner, number of people in household, insurance status, and transportation to doctor visits were considered as predictors.

\section{Variable definitions}

Due to small sample sizes, we limited our analyses to only those who chose either surgery or radiation. We excluded men with unknown or "other" race and a distant or unknown tumor stage. Also, grade was dichotomized into low (grades of 1 or 2: well to moderately differentiated) versus high (grades of 3 or 4: poorly to undifferentiated). Stage was classified as either localized or regional (regional included both regional with extensions and regional to lymph nodes). PSA change was assessed as a dichotomous variable, comparing no PSA change with $\geq 1$ change in PSA since cancer treatment. Because subjects chose multiple options for insurance status, this variable was treated individually as four separate dichotomous variables (Medicaid, Medicare, private insurance, and other). Marital status was dichotomized as married versus unmarried, and previous cancer diagnoses was dichotomized as none versus $\geq 1$ previous diagnosis.

\section{Statistical methods}

We compared responders to non-responders to determine the representativeness of the study sample by reviewing the distributions or frequencies of all variables and computing descriptive statistics. We performed univariable analyses to assess racial, socioeconomic, and treatment differences in reported factors influencing prostate cancer treatment decisions. Significant covariates in the univariable models were included in the full model. Because racial disparities in prostate cancer incidence and treatment choices exist, we considered race as a covariate regardless of its significance in models.

Unconditional logistic regression analyses were performed with treatment as the dependent variable dichotomized as surgery versus radiation. We used separate models for social (doctor, family/friend, self) and clinical (cure, impotence, incontinence, pain) factors, and also stratified models by race to examine possible effect modification of influential factors on treatment choice. Results are presented as odds ratios (OR) and corresponding 95\% confidence intervals (CI). All analyses were performed using SAS v.9.1.3 (SAS Institute, Cary, NC).

\section{Results}

Although survey responders $(n=551)$ were similar to non-responders $(n=1,425)$ in terms of tumor grade, responders tended to be younger, more likely to classify themselves as white and married, and more likely to have a regional tumor stage compared to non-responders (Table 1). Of responders, six did not provide any treatment information and two responded that they did not know what type of treatment they received. We excluded nine (2\%) men because they were not of black or white race, 18 (3\%) because their tumors were distant or unstaged, $20(4 \%)$ because their tumors were of an unknown grade, and $47(9 \%)$ because their treatment was a type other than surgery or radiation or because they chose both surgery and radiation $(n=14)$. There were 435 observations remaining for further analyses.

When each factor was evaluated independently, there was a statistically significant increase in the odds of cases having a regionally staged tumor among those who chose surgery $(n=$ $59)$ compared to those who chose radiation $(n=8)$ (Table 2). Those who chose surgery also 
were less likely to have had $\geq$ change in PSA score, to be younger, unmarried, and to receive Medicare or Medicaid compared to those who chose radiation (Table 2).

Unconditional logistic regression models (Table 3) examined the relationship between clinical and social factors and treatment choice after adjustment for confounding variables identified in univariable models (age at diagnosis, marital status, Medicare and Medicaid insurance coverage, tumor stage, PSA change, and race). Compared to those who chose radiation, those who chose surgery were about twice as likely to have been influenced by a doctor and to consider cure and more than two and a half times more likely to have been influenced by a family member or friend. Those men choosing surgery also were about $60 \%$ less likely to consider incontinence in their decision making.

When models were stratified by race and adjusted for age at diagnosis and tumor stage, white and black men who chose surgery were more likely (i.e., >twice and $~ 5.5$ times, respectively) to have been influenced by a family or friend (Table 4). Black men who chose surgery were $>5$ times more likely to have made independent decisions as compared to black men who chose radiation (Table 4). White men who chose surgery were less likely to consider impotence and incontinence and more likely to consider cure as important clinical outcomes compared to white men who chose radiation. No clinical predictors were identified to be statistically related to treatment choice among black men (Table 4). Despite the lack of a statistical association, it is notable that black men who chose surgery tended to consider cure, impotence, and incontinence and not consider pain as important in their treatment choice when compared to black men who chose radiation.

\section{Discussion}

We assessed social and clinical influences on prostate cancer treatment decisions among black and white men diagnosed with the disease in South Carolina and found that men who chose surgery were more likely to emphasize the influences of family and/or friends. This is consistent with the literature, as spouses are more likely to consider total eradication important $[16,27]$. The amount of direct influence that spouses/partners exert on a final treatment decision is uncertain [27], and results are conflicting [9,28]. For example, some studies demonstrate that spouses often help to support their husbands and gather information, but that they leave the final decision making to their husbands $[4,17,29,30]$.

The experiences of people who have had cancer treatment also influences patient treatment choices $[5,9,14,17,18]$, with friends or colleagues previously diagnosed with prostate cancer having a stronger influence on treatment decisions than spouses [27]. In one study, friends were reported as one of the most frequently used sources of information when making a treatment decision along with the internet and pamphlets provided by the healthcare provider [18]. Diefenbach et al. [9] found that patients choosing surgery were influenced by having known other people who had undergone that treatment, and Davidson et al. [30] found that friends who had been treated for prostate cancer most often recommended active treatment. Prostate cancer support groups also have been cited as valuable sources of information and emotional support both before and after treatment [30, 31]. Furthermore, discussing treatment options within one's social support network has been shown to promote greater positive emotional affect at 1 and 6 months after treatment, perhaps fostering greater coping by allowing for emotional expression and cognitive processing [32].

Although present in men of both races, the influence of family/friends in choosing surgery was stronger among black men than among white men. Research has shown black men and women tend to rely heavily on social support from an extended network of family and 
friends, including influences from faith-based networks for making health-related decisions [25] and have higher levels of medical mistrust [33]. This may explain why the influence was stronger among black men in our study. Our results also suggest an independent decision-making influence predicting surgery, especially among black men. It is important that interventions focus on improving the dissemination of information to men and their social support system concerning decision making prior to the medical encounter and encourage participation in shared decision making prior to the final decision.

Overall, men who chose surgery were more likely to consider physicians as an influencing factor. A previous descriptive study in the same population found that the most important social influence on prostate cancer treatment decisions was physician advice [34]. Several other studies have demonstrated that physicians play an influential role in the treatment decision-making process of their patients [17, 27]. For example, one study showed that physicians serve as the most common source of information for patients diagnosed with early-stage (local) prostate cancer [20]. In addition, Hoffman et al. [19] demonstrated that the treatment recommendation from the physician is the most important determinant of the treatment that is ultimately chosen. The type of treatment recommended by a physician is dependent on physician specialty: urologists nearly universally recommend surgery compared to radiation oncologists, who recommend radiation therapy $[27,35]$. This is important because in the United States, a patient suspected of having prostate cancer will be sent to an urologist for a biopsy who is likely to provide the treatment recommendation [27]. Future studies should strive to collect information on physician specialty.

Participants who chose surgery were more likely to consider cure an important factor than did participants who chose radiation. They also tended to downplay clinical side effects. Similarly, other studies have found patients who choose surgery are most concerned with cancer eradication and likely believe that this treatment type offers the most treatment efficacy $[27,28]$. In fact, the eradication of cancer is a primary concern and important influence in choosing treatments for most patients [27].

Men who chose surgery for their primary treatment type were less likely to identify impotence or incontinence as important clinical side effects. The importance of these side effects is dependent on treatment type, with men concerned about avoiding these side effects less likely to prefer surgery as compared to other non-surgical options, such as radiation therapy [27, 28]. Also, cognitive dissonance could very well have played a role: having made the decision to undergo surgery, men are subsequently more likely to downplay the importance of these side effects after the fact. Another explanation is that treatment side effects are relatively less influential on a man's decision compared to other factors, such as treatment efficacy. This may be due to deliberately down-weighting these factors or due to a real lack of knowledge about these clinical side effects either from not receiving accurate information or from information being presented in a complicated manner [27]. In one study, only two of five men were unconditionally willing to risk side effects to potentially gain some longevity [7]. Feldman-Steward et al. [8] found that the chances of dying of cancer and the effect on the length of life were ranked by less than $20 \%$ of patients as one of the four most important attributes to treatment decision. The four attributes most common were the following: the effect of the treatment on bladder function, the procedure involved, effect on sexual functioning, and chance of PSA rising (i.e., as an indicator of recurrence). Of the possible side effects, incontinence may be the most important influencing factor, whereas impotence may be less influential in treatment decisions [27]. There is evidence that the importance placed on side effects varies by race [36-39]. A patient's perceptions on how a treatment will affect the issues he finds most important may help explain his treatment decision. 
When stratified, the relationship between choosing radiation and a concern for impotence/ incontinence was only seen among whites. It is noteworthy that black men in the current study tended to exhibit an opposite trend as compared to whites, with more emphasis on impotence/ incontinence among black men who chose surgery versus black men who chose radiation. Although a mechanism behind this discordance is unclear based on these data, it may be that black men were differentially affected by cognitive dissonance, perhaps blaming and overstating the influence of these side effects post-surgery. It also may be that black men are not getting appropriate or understandable information from health professionals regarding the potential for short- and long-term side effects.

In general, there is substantial variation in the types of treatments and therapies received by white versus black men, with black men more often receiving less aggressive therapies compared to white men [23, 27, 40]. A study by Richert-Boe et al. [41] found black men were offered and received treatment with curative intent less often than their white counterparts of the same age with the same tumor grade, stage of cancer, and insurance coverage. Other studies also have demonstrated that black men are less likely to receive prostatectomies than white men [19, 21]. Importantly, treatment regret also has been observed in black men and men of low income [40].

Despite the observed variation in this study, there is a paucity of research examining racial differences in influences involved in this decision-making process [27]. In one qualitative study, the authors noted that of the $6 \%$ of subjects who reported not reading any written material while making their decision, all were men of color (5 out of 6 African Americans in the study and 1 out of 1 Asian American). Literacy did not seem to be an issue for these participants [17]. When asked about this in individual interviews, several of these men said they felt their physician had provided sufficient information. Several also expressed a sense of urgency in making a decision quickly to prevent the cancer from spreading. Interestingly, 6 of the 7 non-white participants expressed concern about the spread of the disease as an influential factor versus only 5 of the 24 white men in the study, a finding that appears to run counter to the tendency of white men to prefer surgery.

While it is unclear why these observed differences exist, some hypothesize that it may be due to physician beliefs that black men will be less likely to adhere to medical advice and will be more likely to experience poor outcomes [19]. Others cite the distrust of physicians held by black men and women, their fear of surgery [22], as well as physician's beliefs that black men and women will be less receptive to recommendations for prostatectomy as being responsible for these differences [21]. Finally, black men may tend to weigh influencing factors differently than white men, as they have been found to consider cure less important and pain more important when making a treatment decision [34]. More research is needed in this area, especially because black men have been found to have significantly higher rates of prostate cancer incidence and mortality than any other racial group or ethnic group [24], especially in South Carolina [25].

We collected data for the current study with a short mail questionnaire that was selfadministered by men previously diagnosed with prostate cancer. Therefore, the data may be subject to recall bias, although deciding on a course of treatment for cancer is an important decision that would likely be accurately reported. Additionally, because the survey was administered after the men made the decision of treatment type, cognitive dissonance may very well have influenced our results, although the extent to which this occurred is unknown. This dissonance may have acted in several ways. For example and as noted earlier, men who chose surgery may subsequently downplay the importance of side effects in their treatment decision or, alternatively, men who chose surgery and then experienced side effects as a result of their decision may subsequently overemphasize the importance or 
their understanding of side effects in their treatment decision-making process. Studies collecting similar data prior to decision making and/or the collection of information on the side effects experienced post-treatment would help circumvent this limitation or allow its quantification.

Although we had a reasonable response rate (28\%), men who responded to the survey were more likely to be younger, white, married, and diagnosed with more regional tumors. Despite underrepresentation of black men, we were able to stratify our model by race to assess important racial differences in the influences of prostate cancer treatment. Future studies should attempt to obtain a sample with a higher rate of black representation. It is possible that we received responses from a more health conscious and informed group of men. The extent to which this may have influenced our results is unknown. Men in good health are offered surgery more frequently as a treatment for prostate cancer; therefore, our sample may have included a larger proportion of men who chose surgery. It is also possible that healthier or more health-conscious men are influenced differently; for example, men in poorer health may be less concerned about side effects and more concerned about cure.

Additionally, we were unable to evaluate treatments other than surgery and radiation due to a limited sample size. Future studies should strive to achieve a larger sample size of men with different treatment types, especially watchful waiting, as this is an important treatment option for prostate cancer. Despite this limitation, excluding both adjuvant therapies and hormone therapy excludes the highest-risk tumors, and men with extremely high-risk tumors may undergo a very different process in selecting treatment.

Our study is one of few to examine the social influences on prostate cancer treatment choices. Additionally, this study is unique in its examination of racial disparities in these types of choices. It is important to understand what types of influences-whether they are personal, social, or clinical-have the greatest impact on decision making in prostate cancer so that public health officials and physicians can provide better information to relevant social networks and on relevant clinical topics.

In summary, our study provides an important questionnaire-based assessment of the social and clinical influences of prostate cancer treatment choices among white and black men in South Carolina. Our results demonstrate that men of both races who chose surgery were more likely to be influenced by their physician and family/friends, and black men who chose surgery were more likely to make independent decisions compared to men who chose radiation. White men who chose surgery were more likely to be influenced by cure and less likely to be influenced by the side effects of impotence or incontinence. In contrast, our results suggest an opposite effect in black men, with those who chose surgery tending to be more influenced by side effects. Additional studies should seek to further clarify social influences and racial differences in prostate cancer treatment choices.

\section{Acknowledgments}

This work was supported, in part, by grant number 1 U01 CA114601 from the National Cancer Institute, Center to Reduce Cancer Health Disparities (Community Networks Program) to the South Carolina Cancer Disparities Community Network. Dr. Wagner is currently funded by a grant from the Georgia Cancer Coalition (Proposal number 038505). Dr. Hébert is supported by an Established Investigator Award in Cancer Prevention and Control from the Cancer Training Branch of the National Cancer Institute (K05 CA136975). Dr. Drake is supported by PC081669 from the Department of Defense.

\section{Abbreviations}

CI Confidence interval 

OR
Odds ratio
PSA
Prostate-specific antigen
SCCCR
South Carolina Central Cancer Registry

\section{References}

1. Wilt TJ, MacDonald R, Rutks I, Shamliyan TA, Taylor BC, Kane RL. Systematic review: comparative effectiveness and harms of treatments for clinically localized prostate cancer. Ann Intern Med. 2008; 148(6):435-448. [PubMed: 18252677]

2. Davison BJ, Degner LF, Morgan TR. Information and decision-making preferences of men with prostate cancer. Oncol Nurs Forum. 1995; 22(9):1401-1408. [PubMed: 8539181]

3. Maliski SL, Heilemann MV, McCorkle R. From “death sentence" to "good cancer": couples' transformation of a prostate cancer diagnosis. Nurs Res. 2002; 51(6):391-397. [PubMed: 12464759]

4. Srirangam SJ, Pearson E, Grose C, Brown SC, Collins GN, O'Reilly PH. Partner's influence on patient preference for treatment in early prostate cancer. BJU Int. 2003; 92(4):365-369. [PubMed: 12930420]

5. O'Rourke ME. Decision making and prostate cancer treatment selection: a review. Semin Oncol Nurs. 2001; 17(2):108-117. [PubMed: 11383242]

6. Fischer M, Visser A, Voerman B, Garssen B, van Andel G, Bensing J. Treatment decision making in prostate cancer: patients' participation in complex decisions. Patient Educ Couns. 2006; 63(3): 308-313. [PubMed: 16965887]

7. Volk RJ, Cantor SB, Cass AR, Spann SJ, Weller SC, Krahn MD. Preferences of husbands and wives for outcomes of prostate cancer screening and treatment. J Gen Intern Med. 2004; 19(4):339-348. [PubMed: 15061743]

8. Feldman-Stewart D, Brundage MD, Van Manen L, Svenson O. Patient-focused decision-making in early-stage prostate cancer: insights from a cognitively based decision aid. Health Expect. 2004; 7(2):126-141. [PubMed: 15117387]

9. Diefenbach MA, Dorsey J, Uzzo RG, Hanks GE, Greenberg RE, Horwitz E, et al. Decision-making strategies for patients with localized prostate cancer. Semin Urol Oncol. 2002; 20(1):55-62. [PubMed: 11828358]

10. Gwede CK, Pow-Sang J, Seigne J, Heysek R, Helal M, Shade K, et al. Treatment decision-making strategies and influences in patients with localized prostate carcinoma. Cancer. 2005; 104(7): 1381-1390. [PubMed: 16080181]

11. Holmboe ES, Concato J. Treatment decisions for localized prostate cancer: asking men what's important. J Gen Intern Med. 2000; 15(10):694-701. [PubMed: 11089712]

12. Hall JD, Boyd JC, Lippert MC, Theodorescu D. Why patients choose prostatectomy or brachytherapy for localized prostate cancer: results of a descriptive survey. Urology. 2003; 61(2): 402-407. [PubMed: 12597956]

13. Mazur DJ, Hickam DH. Patient preferences for management of localized prostate cancer. West J Med. 1996; 165(1-2):26-30. [PubMed: 8855681]

14. Steginga SK, Occhipinti S, Gardiner RA, Yaxley J, Heathcote P. Making decisions about treatment for localized prostate cancer. BJU Int. 2002; 89(3):255-260. [PubMed: 11856106]

15. Potosky AL, Davis WW, Hoffman RM, Stanford JL, Stephenson RA, Penson DF, et al. Five-year outcomes after prostatectomy or radiotherapy for prostate cancer: the prostate cancer outcomes study. J Natl Cancer Inst. 2004; 96(18):1358-1367. [PubMed: 15367568]

16. Chapple A, Ziebland S, Herxheimer A, McPherson A, Shepperd S, Miller R. Is 'watchful waiting' a real choice for men with prostate cancer? A qualitative study. BJU Int. 2002; 90(3):257-264. [PubMed: 12133062]

17. Berry DL, Ellis WJ, Woods NF, Schwien C, Mullen KH, Yang C. Treatment decision-making by men with localized prostate cancer: the influence of personal factors. Urol Oncol. 2003; 21(2):93100. [PubMed: 12856636] 
18. Berry DL, Ellis WJ, Russell KJ, Blasko JC, Bush N, Blumenstein B, et al. Factors that predict treatment choice and satisfaction with the decision in men with localized prostate cancer. Clin Genitourin Cancer. 2006; 5(3):219-226. [PubMed: 17239276]

19. Hoffman RM, Harlan LC, Klabunde CN, Gilliland FD, Stephenson RA, Hunt WC, et al. Racial differences in initial treatment for clinically localized prostate cancer. Results from the prostate cancer outcomes study. J Gen Intern Med. 2003; 1810:845-853. [PubMed: 14521648]

20. Ramsey SD, Zeliadt SB, Arora NK, Potosky AL, Blough DK, Hamilton AS, et al. Access to information sources and treatment considerations among men with local stage prostate cancer. Urology. 2009; 74(3):509-515. [PubMed: 19589564]

21. Denberg TD, Beaty BL, Kim FJ, Steiner JF. Marriage and ethnicity predict treatment in localized prostate carcinoma. Cancer. 2005; 103(9):1819-1825. [PubMed: 15795905]

22. Shankar S, Selvin E, Alberg AJ. Perceptions of cancer in an African-American community: a focus group report. Ethn Dis. 2002; 12(2):276-283. [PubMed: 12019938]

23. Pisu M, Oliver JS, Kim YI, Elder K, Martin M, Richardson LC. Treatment for older prostate cancer patients: disparities in a southern state. Med Care. 2010; 48(10):915-922. [PubMed: 20733530]

24. Altekruse, SF.; Kosary, CL.; Krapcho, M.; Neyman, N.; Aminou, R.; Waldron, W., et al. SEER cancer statistics review, 1975-2007. National Cancer Institute; Bethesda, MD: 2010. http://seer.cancer.gov/csr/1975_2007/, based on November 2009 SEER data submission, posted to the SEER web site

25. Drake BF, Keane TE, Mosley CM, Adams SA, Elder KT, Modayil MV, et al. Prostate cancer disparities in South Carolina: early detection, special programs, and descriptive epidemiology. J S C Med Assoc. 2006; 102:241-249. [PubMed: 17319238]

26. Greene, FL.; Page, DL.; Fleming, ID. American Join Committee on Cancer. 6th edn. Springer; New York: 2002.

27. Zeliadt SB, Ramsey SD, Penson DF, Hall IJ, Ekwueme DU, Stroud L, et al. Why do men choose one treatment over another? A review of patient decision making for localized prostate cancer. Cancer. 2006; 106:1865-1874. [PubMed: 16568450]

28. Zeliadt SB, Moinpour CM, Blough DK, Penson DF, Hall IJ, Smith JL, et al. Preliminary treatment considerations among men with newly diagnosed prostate cancer. Am J Manag Care. 2010; 16(5):e121-e130. [PubMed: 20455638]

29. O'Rourke ME. Choose wisely: therapeutic decisions and quality of life in patients with prostate cancer. Clin J Oncol Nurs. 2007; 11(3):401-408. [PubMed: 17623624]

30. Davidson JB, Oliffe JL, Pickles T, Mroz L. Factors influencing men undertaking active surveillance for the management of low-risk prostate cancer. Oncol Nurs Forum. 2009; 36(1):8.

31. Cox J, Amling CL. Current decision-making in prostate cancer therapy. Curr Opin Urol. 2008; 18(3):275-278. [PubMed: 18382237]

32. Christie KM, Meyerowitz BE, Giedzinska-Simons A, Gross M, Agus DB. Predictors of affect following treatment decision-making for prostate cancer: conversations, cognitive processing, and coping. Psychooncology. 2009; 18(5):508-514. [PubMed: 18756584]

33. Talcott JA, Spain P, Clark JA, Carpenter WR, Do YK, Hamilton RJ, et al. Hidden barriers between knowledge and behavior: the North Carolina prostate cancer screening and treatment experience. Cancer. 2007; 15:1599-1606. [PubMed: 17354220]

34. Elder K, Drake BF, Wagner S, Hebert J. An examination of the social and clinical influences in prostate cancer treatment in African American and White men. J Health Dispar Res Pract. 2008; 2(2):125-131.

35. Lin GA, Aaronson DS, Knight SJ, Carroll PR, Dudley RA. Patient decision aids for prostate cancer treatment: a systematic review of the literature. CA Cancer J Clin. 2009; 59:379-390. [PubMed: 19841280]

36. Kilbridge KL, Fraser G, Krahn M, Nelson EM, Conaway M, Bashore R, et al. Lack of comprehension of common prostate cancer terms in an underserved population. J Clin Oncol. 2009; 27(12):2015-2021. [PubMed: 19307512]

37. Klein JB, Nguyen CT, Saffore L, Modlin C III, Modlin CS Jr. Racial disparities in urologic health care. J Natl Med Assoc. 2010; 102(2):108-117. [PubMed: 20191923] 
38. Maliski SL, Rivera S, Connor S, Lopez G, Litwin MS. Renegotiating masculine identity after prostate cancer treatment. Qual Health Res. 2008; 18(12):1609-1620. [PubMed: 18955461]

39. Ukoli FA, Lynch BS, Adams-Campbell LL. Radical prostatectomy and quality of life among African Americans. Ethn Dis. 2006; 16(4):988-993. [PubMed: 17061757]

40. Moses KA, Paciorek AT, Penson DF, Carroll PR, Master VA. Impact of ethnicity on primary treatment choice and mortality in men with prostate cancer: data from CaPSURE. J Clin Oncol. 2010; 28(6):1069-1074. [PubMed: 20100957]

41. Richert-Boe KE, Weinmann S, Shapiro JA, Rybicki BA, Enger SM, Van Den Eeden SK, et al. Racial differences in treatment of early-stage prostate cancer. Urology. 2008; 71(6):1172-1176. [PubMed: 18279922] 
Table 1

Descriptive characteristics of men by response status

\begin{tabular}{|c|c|c|c|}
\hline Characteristics & $\begin{array}{c}\text { Responders } \\
(n=551) \\
n(\%)\end{array}$ & $\begin{array}{c}\operatorname{con}^{\text {Non-responders }}{ }^{a} \\
(n=1,425) \\
n(\%)\end{array}$ & $X^{2}(p$ value $)$ \\
\hline Age at diagnosis (mean[SD]) $t$ test & $64(8)$ & $66(9)$ & $4.1(<0.0001)$ \\
\hline Race & & & $147(<0.0001)$ \\
\hline White & $432(78)$ & $689(48)$ & \\
\hline Black & $110(20)$ & $699(49)$ & \\
\hline Other & $6(1)$ & $20(1)$ & \\
\hline Unknown & $3(0.5)$ & $17(1)$ & \\
\hline Marital status & & & $24.9(<0.0001)$ \\
\hline Unmarried (sep, div, wid) & $60(11)$ & $279(20)$ & \\
\hline Married & $471(85)$ & $1,072(75)$ & \\
\hline Unknown & $20(4)$ & $74(5)$ & \\
\hline Tumor grade & & & $4.4(0.35)$ \\
\hline Well differentiated & $42(8)$ & $125(9)$ & \\
\hline Moderately differentiated & $395(72)$ & $956(67)$ & \\
\hline Poorly differentiated & $83(15)$ & $242(17)$ & \\
\hline Undifferentiated & $2(0.4)$ & $4(0.3)$ & \\
\hline Not determined & $29(5)$ & $98(7)$ & \\
\hline Tumor stage & & & $15.3(0.002)$ \\
\hline Localized & $442(80)$ & $1,149(81)$ & \\
\hline Regional & $81(15)$ & $149(10)$ & \\
\hline Distant metastasized & $3(0.5)$ & $30(2)$ & \\
\hline Unstaged & $25(5)$ & $97(7)$ & \\
\hline
\end{tabular}


Table 2

Univariate statistics modeling the effect of clinical and sociodemographic factors on surgery versus radiation as a primary prostate cancer treatment type

\begin{tabular}{|c|c|c|c|}
\hline Variable & Surgery & $\begin{array}{c}\text { Radiation } \\
(n=253) \\
n(\%)\end{array}$ & $\begin{array}{l}\text { OR }(95 \% \text { CI }) \\
(n=182) n(\%)\end{array}$ \\
\hline \multicolumn{4}{|l|}{ Race } \\
\hline White & $201(79)$ & $149(82)$ & 1.00 \\
\hline Black & $52(21)$ & $33(18)$ & $1.17(0.72,1.90)$ \\
\hline \multicolumn{4}{|l|}{ Tumor stage } \\
\hline Localized & $194(77)$ & $174(96)$ & $1.00^{a}$ \\
\hline Regional & $59(23)$ & $8(4)$ & $6.62(3.07,14.23)$ \\
\hline \multicolumn{4}{|l|}{ Tumor grade } \\
\hline Low $($ grade $=1$ or 2$)$ & $218(86)$ & $155(85)$ & 1.00 \\
\hline High $($ grade $=3$ or 4$)$ & $35(14)$ & $27(15)$ & $0.92(0.54,1.59)$ \\
\hline \multicolumn{4}{|l|}{ PSA change } \\
\hline No change & $115(46)$ & $38(21)$ & $1.00^{a}$ \\
\hline$\geq 1$ change & $134(54)$ & $140(79)$ & $0.32(0.20,0.49)$ \\
\hline Age at diagnosis (years) & $61(7)$ & $68(8)$ & $0.88(0.86,0.91)^{a}$ \\
\hline \multicolumn{4}{|l|}{ Marital status } \\
\hline Married & $230(93)$ & $152(84)$ & $1.00^{a}$ \\
\hline Unmarried & $18(7)$ & $28(16)$ & $0.43(0.23,0.80)$ \\
\hline \multicolumn{4}{|l|}{ Prior cancer diagnoses } \\
\hline None & $231(91)$ & $160(88)$ & 1.00 \\
\hline$\geq 1$ & $22(9)$ & $22(12)$ & $0.69(0.37,1.29)$ \\
\hline \multicolumn{4}{|l|}{ Insurance $^{b}$} \\
\hline Medicare & $160(63)$ & $153(84)$ & $0.33(0.20,0.52)^{a}$ \\
\hline Medicaid & $9(4)$ & $15(8)$ & $0.41(0.18,0.96)^{a}$ \\
\hline Private & $118(47)$ & $69(38)$ & $1.43(0.97,2.11)$ \\
\hline Other & $110(44)$ & $78(43)$ & $1.03(0.70,1.51)$ \\
\hline \multicolumn{4}{|l|}{ Social predictors } \\
\hline Doctor & $143(57)$ & $105(58)$ & $0.95(0.65,1.40)$ \\
\hline Family/friend & $70(28)$ & $32(18)$ & $1.79(1.12,2.87)^{a}$ \\
\hline Yourself & $94(37)$ & $69(38)$ & $0.97(0.65,1.44)$ \\
\hline \multicolumn{4}{|l|}{ Clinical predictors } \\
\hline Cure & $218(86)$ & $137(75)$ & $2.05(1.25,3.34)^{a}$ \\
\hline Impotence & $41(16)$ & $60(33)$ & $0.39(0.25,0.62)^{a}$ \\
\hline Incontinence & $30(12)$ & $59(32)$ & $0.28(0.17,0.46)^{a}$ \\
\hline Pain & $9(4)$ & $13(7)$ & $0.48(0.20,1.15)$ \\
\hline
\end{tabular}

OR odds ratio, CI confidence interval, PSA prostate-specific antigen 
${ }^{a}$ Overall $p$ value $<0.05$

${ }^{b}$ Treated as individual dichotomous variable because of multiple responses per individual 
Table 3

Adjusted effects of clinical and social predictors on prostate cancer treatment choice (surgery vs. radiation) ( $n$ $=435$ )

\begin{tabular}{|c|c|c|}
\hline Variable & Odds ratio & $\begin{array}{l}\text { 95\% confidence } \\
\text { interval }\end{array}$ \\
\hline \multicolumn{3}{|l|}{ Social predictors ${ }^{a}$} \\
\hline Doctor & 1.99 & $1.09,3.64$ \\
\hline Family/friend & 2.64 & $1.35,5.14$ \\
\hline Yourself & 1.73 & $0.95,3.17$ \\
\hline Age at diagnosis (years) & 0.87 & $0.84,0.91$ \\
\hline \multicolumn{3}{|l|}{ Marital status (vs. married) } \\
\hline Unmarried & 0.65 & $0.30,1.42$ \\
\hline \multicolumn{3}{|l|}{ Insurance } \\
\hline Medicare & 1.22 & $0.61,2.43$ \\
\hline Medicaid & 0.50 & $0.17,1.51$ \\
\hline \multicolumn{3}{|l|}{ Stage (vs. localized) } \\
\hline Regional & 7.32 & $3.10,17.28$ \\
\hline \multicolumn{3}{|c|}{ PSA change (vs. no change) } \\
\hline$\geq 1$ change & 0.33 & $0.20,0.54$ \\
\hline \multicolumn{3}{|l|}{ Race (vs. White) } \\
\hline Black & 0.94 & $0.51,1.75$ \\
\hline \multicolumn{3}{|l|}{ Clinical predictors $^{a}$} \\
\hline Cure & 2.37 & $1.25,4.50$ \\
\hline Impotence & 0.52 & $0.27,1.02$ \\
\hline Incontinence & 0.42 & $0.20,0.84$ \\
\hline Pain & 0.84 & $0.24,2.93$ \\
\hline Age at diagnosis (years) & 0.87 & $0.83,0.91$ \\
\hline \multicolumn{3}{|l|}{ Marital status (vs. married) } \\
\hline Unmarried & 0.60 & $0.27,1.33$ \\
\hline \multicolumn{3}{|l|}{ Insurance } \\
\hline Medicare & 1.21 & $0.59,2.48$ \\
\hline Medicaid & 0.62 & $0.21,1.86$ \\
\hline \multicolumn{3}{|l|}{ Stage (vs. localized) } \\
\hline Regional & 7.18 & $2.98,17.33$ \\
\hline \multicolumn{3}{|c|}{ PSA change (vs. no change) } \\
\hline$\geq 1$ change & 0.33 & $0.19,0.55$ \\
\hline \multicolumn{3}{|l|}{ Race (vs. White) } \\
\hline Black & 1.22 & $0.62,2.37$ \\
\hline
\end{tabular}


Table 4

Relationship of clinical and social predictors and prostate cancer treatment choice (surgery vs. radiation), stratified by race $(n=435)$

\begin{tabular}{|c|c|c|c|c|}
\hline \multirow[t]{2}{*}{ Variable } & \multicolumn{2}{|c|}{ White $(n=350)$} & \multicolumn{2}{|c|}{ Black $(\mathbf{n}=85)$} \\
\hline & Odds ratio & $95 \% \mathrm{CI}$ & Odds ratio & $95 \% \mathrm{CI}$ \\
\hline \multicolumn{5}{|l|}{ Social predictors ${ }^{a}$} \\
\hline Doctor & 1.79 & $0.95,3.40$ & 1.95 & $0.51,7.42$ \\
\hline Family/friend & 2.31 & $1.16,4.61$ & 5.51 & $1.21,25.09$ \\
\hline Yourself & 1.30 & $0.69,2.48$ & 5.35 & $1.22,23.60$ \\
\hline Age at diagnosis (years) & 0.88 & $0.85,0.91$ & 0.81 & $0.73,0.90$ \\
\hline \multicolumn{5}{|l|}{ Stage (vs. localized) } \\
\hline Regional & 12.88 & $1.35,38.11$ & 0.78 & $0.17,3.71$ \\
\hline \multicolumn{5}{|l|}{ Clinical predictors } \\
\hline Cure & 2.20 & $1.07,4.55$ & 1.87 & $0.60,5.80$ \\
\hline Impotence & 0.40 & $0.18,0.88$ & 1.37 & $0.36,5.17$ \\
\hline Incontinence & 0.27 & $0.12,0.63$ & 1.55 & $0.41,5.95$ \\
\hline Pain & 1.28 & $0.28,5.95$ & 0.33 & $0.06,1.76$ \\
\hline Age at diagnosis (years) & 0.87 & $0.83,0.90$ & 0.83 & $0.75,0.91$ \\
\hline \multicolumn{5}{|l|}{ Stage (vs. localized) } \\
\hline Regional & 12.34 & $4.06,37.56$ & 1.14 & $0.25,5.26$ \\
\hline
\end{tabular}

Black: Surgery, $n=52$. Radiation, $n=33$ White: Surgery, $n=201$. Radiation, $n=149$ CI confidence interval

${ }^{a}$ Social and clinical predictors run in separate logistic regression models 